\title{
Di-(2-ethylhexyl) dithiophosphoric acid surface protected gold nanoparticles: micellar synthesis, stabilization, isolation, and properties
}

\author{
Vladimir V. Tatarchuk • Anastasiya P. Sergievskaya • Alexander I. Bulavchenko • \\ Vladimir I. Zaikovsky • Irina A. Druzhinina • Tamara M. Korda • Pavel N. Gevko • \\ Alexey V. Alexeyev
}

Published online: 6 October 2011

(C) The Author(s) 2011. This article is published with open access at Springerlink.com

\begin{abstract}
Gold nanoparticles (AuNPs) were synthesized in the organic solution by means of the reduction of $\mathrm{HAuCl}_{4}$ by hydrazine in reverse micelles of oxyethylated surfactant Triton N-42, with decane as the dispersion medium. To isolate the powder of particles, the micelles were destroyed with chloroform in the presence of di-(2-ethylhexyl) dithiophosphoric acid as a surface protecting agent. According to the results of several experiments, the yield is within the limits of $90-98 \%$, calculated for gold. The obtained preparations are dark blue hydrophobic powders containing aggregated but not agglomerated gold nanoparticles, as well as microcrystals $(\sim 0.08-0.2 \mu \mathrm{m})$ of $\mathrm{NaCl}$. The powders get re-dispersed in weakly polar organic solvents with the formation of colloidal solutions. The shape of the nanoparticles is spherical. Their nuclei are gold single crystals with a narrow size distribution; their diameter $\left(d_{\mathrm{Au}}\right)$ is about two times as large as the diameter of the aqueous nucleus $\left(d_{\mathrm{c}}\right)$ of initial micelles: $d_{\mathrm{Au}}=7.7 \pm$ $1.4 \mathrm{~nm}\left(d_{\mathrm{c}}=3.6 \mathrm{~nm}\right)$ and $8.8 \pm 1.5 \mathrm{~nm}(4.6 \mathrm{~nm})$. The preparations were studied by means of dynamic light scattering, atomic force microscopy, transmission electron microscopy, UV-vis spectroscopy, IR spectroscopy, X-ray
\end{abstract}

V. V. Tatarchuk - A. P. Sergievskaya $(\bowtie) \cdot$ A. I. Bulavchenko I. A. Druzhinina $\cdot$ T. M. Korda $\cdot$ P. N. Gevko $\cdot$ A. V. Alexeyev Nikolaev Institute of Inorganic Chemistry, Siberian Branch, Russian Academy of Sciences,

Ac. Lavrentyev pr., 3,

Novosibirsk 630090, Russia

e-mail: sergievskaya@niic.nsc.ru

\section{I. Zaikovsky}

Boreskov Institute of Catalysis, Siberian Branch,

Russian Academy of Sciences,

Ac. Lavrentyev pr., 5,

Novosibirsk 630090, Russia powder diffraction, and thermogravimetric and elemental analyses. In the case of the particles with $d_{\mathrm{Au}}=8.8 \mathrm{~nm}$, the product is a mixture of AuNPs and the salt with the molar ratio $\mathrm{Au} / \mathrm{NaCl} \approx 1: 4.54$, while the gross composition of AuNPs per one gold atom is estimated as $\mathrm{Au}\left(\mathrm{C}_{16} \mathrm{H}_{34} \mathrm{O}_{2} \mathrm{P}\right.$ $\left.\mathrm{S}_{2} \mathrm{Na} 2 \mathrm{~N}_{2} \mathrm{H}_{4}\right)_{0.16}$ with the number of gold atoms in one particle $\sim 21,000$.

Keywords Gold nanoparticles · Reverse micelles · Triton N-42 surfactant $\cdot$ Di-(2-ethylhexyl) dithiophosphoric acid

\section{Introduction}

Gold nanoparticles (AuNPs) are very important for advanced materials and nanotechnology first of all due to their electron, optical, and catalytic properties [1-5]. Among a number of the methods of their preparation, rather widespread one is chemical reduction of gold species in solutions including homogeneous [6, 7], heterogeneous [8$10]$, and colloidal $[11,12]$ systems. Synthesis in reverse micelles is one of the efficient methods of obtaining nanoparticles with a narrow size distribution due to the possibility of purposeful adjustment of micelle structure through dosed solubilization of the disperse aqueous phase (DAP) [12-15].

Previously, we studied the kinetics of growth and oxidative dissolution of gold and silver nanoparticles in the reverse micelles of surfactants [16-21]. The particle formation occurs inside the polar cavities of reverse micelles during the reduction of the ionic species of metals present in DAP. The isolation of particles from the colloidal solution in the form of the powdered solid phase is achieved due to the destruction of micelles with a polar 
solvent. The problem of the conservation of the initial size of nanoparticles during the isolation process is a very urgent task, so the isolation of the particles is performed in the presence of a protective agent preventing their agglomeration. Different types of protective reagents for gold nanoparticles are known, in particular citrate ion $[6,7]$, alkylthiols [22-24], alkylthioacetates [25], organic amines [26, 27], and phosphines [28].

The goal of the present work was to develop a method of synthesis, stabilization, and isolation of AuNPs from micellar solutions of Triton N-42 with the conservation of initial size, as well as examination of some physiochemical characteristics of the resulting preparations. The protective reagents for stabilization were AOT (intermediate protective reagent) and di-(2-ethylhexyl) dithiophosphoric acid (major stabilizing agent). Di-(2-ethylhexyl) dithiophosphoric acid had not been used previously for particle stabilization, but it is well known as a selective extracting agent for nonferrous and noble metals [29-32].

\section{Experimental section}

The reagents used in the work were: metal gold (+99.95\%); chemically pure grade, concentrated aqueous solutions of $\mathrm{HCl}$ and hydrazine; pure grade di-(2-ethylhexyl) dithiophosphoric acid $\left(\mathrm{C}_{16} \mathrm{H}_{34} \mathrm{O}_{2} \mathrm{PS}_{2} \mathrm{H}\right.$, DTPA $), n$-decane, $n$ heptane, chloroform, and toluene; Triton N-42 (TN-42) and sodium bis-(2-ethylhexyl) sulfosuccinate (AOT) surfactants by Sigma.

Crystalline $\mathrm{HAuCl}_{4} \cdot 3 \mathrm{H}_{2} \mathrm{O}$ was synthesized from metal $\mathrm{Au}$ according to the conventional procedure [33].

Standard solutions $0.23 \mathrm{M} \mathrm{HAuCl}_{4}, 2 \mathrm{M}$ DTPA, $0.25 \mathrm{M}$ $\mathrm{TN}-42$, and $0.25 \mathrm{M}$ AOT were prepared by dissolving the weighed portions of reagents in the aqueous solution of $3 \mathrm{M} \mathrm{HCl}$, toluene, decane, and chloroform, respectively.

Synthesis of AuNPs Nanoparticles were synthesized through the reduction of tetrachloroauric acid by hydrazine in TN-42 reverse micelles at the solubilization capacity of micellar solution $V_{\mathrm{s}} / V_{\mathrm{o}}=0.005$ and $0.02\left(V_{\mathrm{s}} / V_{\mathrm{o}}\right.$ - the volume ratio of dispersed aqueous and organic phases). The micellar solutions of $\mathrm{HAuCl}_{4}(\mathrm{~A})$ and $\mathrm{N}_{2} \mathrm{H}_{4}$ (B) were made by means of injection solubilization of $20 \mu \mathrm{L}$ (or $80 \mu \mathrm{L}$ ) of the aqueous solution of $0.23 \mathrm{M} \mathrm{HAuCl}_{4}$ or concentrated $\mathrm{N}_{2} \mathrm{H}_{4}(\sim 20 \mathrm{M})$ into $4 \mathrm{~mL}$ solution of $0.25 \mathrm{M} \mathrm{TN}-42$ in decane. To synthesize AuNPs, the solutions A and B having equal $V_{\mathrm{s}} / V_{\mathrm{o}}$ were mixed at room temperature in the volume ratio of $1: 1$. The color of the reaction mixture changed from yellow to deep red indicating the formation of AuNPs. The micellar solutions of synthesized AuNPs were stable for 6 months and had the conventional SPR band at $525 \mathrm{~nm}$.
Isolation of NPs from micellar solution To precipitate AuNPs from the TN-42 solution, micelles were destroyed by chloroform in the presence of stabilizing agents. In typical experiment, $8 \mathrm{~mL}$ of AuNPs micellar solution in decane was mixed with the $8 \mathrm{~mL}$ solution of $0.25 \mathrm{M}$ AOT in chloroform and $0.46 \mathrm{~mL}$ solution of $2 \mathrm{M}$ DTPA in toluene. There was an instant color change to blue after mixing the solutions. The resulting dark blue powder of nanoparticles was separated from the colorless solution of the surfactant by centrifuging, washed by decantation with chloroform and heptane, and dried in the air to the constant mass.

Instrumentation and measurements The hydrodynamic diameters of the micelles of the surfactant $\left(d_{\mathrm{hm}}\right)$, AuNPs in micellar solutions during synthesis $\left(d_{\mathrm{hp}}\right)$, and in colloidal solutions prepared through re-dispersion of the preparation of particles in toluene $\left(d_{\text {ha }}\right)$ were measured by dynamic light scattering (DLS) method at an angle of $90^{\circ}$ in a quartz cell with a section of $1 \times 1 \mathrm{~cm}^{2}$ at a temperature of $T=20^{\circ} \mathrm{C}$ with 90Plus spectrometer (Brookhaven Inst). The solutions were de-dusted preliminarily by passing them many times through a glass filter with the pores $0.5 \mu \mathrm{m}$ in diameter. The standard deviation of the determined average values of the hydrodynamic diameters, with the number of measurements more than 20 , did not exceed $0.2 \mathrm{~nm}$. In the synthesis of AuNPs, the initial size of reverse micelles of TN-42 was governed by changing the solubilization capacity $V_{\mathrm{s}} / V_{\mathrm{o}}$ of the micellar solution in agreement with the known dependence $d_{\mathrm{hm}}=d_{0}+b V_{\mathrm{s}} / V_{\mathrm{o}}[34,35]$, where $V_{\mathrm{s}}$ and $V_{\mathrm{o}}$ are the volumes of solubilized DAP and micellar solution, $b$ is an empirical constant, $d_{0}$ is the hydrodynamic diameter of "dry" micelles in the absence of DAP $\left(V_{\mathrm{s}}=0\right)$. In fact, $d_{0}=$ $5.6 \mathrm{~nm}$, measured by means of DLS for the solution of $0.25 \mathrm{M} \mathrm{TN}-42$ in decane, is close to the doubled length of TN-42 molecule [36]. The diameters of the water nuclei of micelles $\left(d_{\mathrm{c}}\right)$ and the gold nuclei of nanoparticles $\left(d_{\mathrm{Au}}\right)$ were determined as $d_{\mathrm{c}}=d_{\mathrm{hm}}-d_{0}$ and $d_{\mathrm{Au}}=d_{\mathrm{hp}}-d_{0}$ assuming the spherical shape of micelles. At $V_{\mathrm{s}} / V_{\mathrm{o}}=0.005$ and 0.02 , the initial micelles of $\mathrm{TN}-42$ have the size of the water nucleus $d_{\mathrm{c}}=3.6$ and $4.6 \mathrm{~nm}$ (Table 1 ).

Table 1 Size characteristics of initial micelles of TN-42 and AuNPs synthesized in them, $d_{0}=5.6 \mathrm{~nm}$

\begin{tabular}{|c|c|c|c|c|c|}
\hline \multirow[t]{2}{*}{$V_{\mathrm{s}} / V_{\mathrm{o}}$} & \multicolumn{2}{|l|}{$\mathrm{a}$} & \multicolumn{3}{|l|}{$\mathrm{b}$} \\
\hline & $d_{\mathrm{hm}}(\mathrm{nm})$ & $d_{\mathrm{c}}(\mathrm{nm})$ & $d_{\mathrm{hp}}(\mathrm{nm})$ & $\begin{array}{l}d_{\mathrm{Au}}(\mathrm{nm}) \\
\text { (DLS) }\end{array}$ & $\begin{array}{l}d_{\mathrm{Au}}(\mathrm{nm}) \\
(\mathrm{TEM})^{\mathrm{a}}\end{array}$ \\
\hline 0.005 & 9.2 & 3.6 & 13.5 & 7.9 & $7.7 \pm 1.4$ \\
\hline 0.02 & 10.2 & 4.6 & 14.1 & 8.5 & $8.8 \pm 1.5$ \\
\hline
\end{tabular}

$a$ initial micelles of TN-42, $b$ AuNPs synthesized in initial micelles of $\mathrm{TN}-42$

${ }^{\text {a }}$ Confidence interval for probability $P=0.95$ 
Examination of the nanoparticle preparation by means of atomic force microscopy (AFM) was performed in the semi-contact mode with the scanning probe microscope Solver Pro (NT-MDT) in the air. The samples were prepared by depositing a drop of the colloidal solution of the preparation in toluene on the substrate made of mica and by subsequent evaporation of the solvent.

The morphology and size of individual nanoparticles in preparations were studied with the transmission electron microscope JEM-2010 (JEOL) with the accelerating voltage of $200 \mathrm{kV}$. To prepare the sample, a drop of the solution of particle preparation in toluene treated with ultrasound was dried on the substrate made of 200-mesh copper grid covered with a "holey" carbon film. Local energy-dispersive X-ray spectroscopy (EDX) analysis of the preparations was performed with EDAX spectrometer (EDAX Co) with Si-Li detector.

$\mathrm{X}$-ray powder diffraction (XRD) data were obtained with a DRON-3M diffractometer $\left(R=192 \mathrm{~mm}, \mathrm{Cu} K_{\alpha}\right.$ radiation, $\mathrm{Ni}$-filter, scintillation point detector with amplitude discrimination) at the room temperature over the range 5-60 $2 \theta$ with step $0.03^{\circ}$ in $2 \theta$ and $1 \mathrm{~s}$ counting time per step. The samples were prepared by grinding the powder in agate mortar with heptane and further deposition of this suspension on the polished side of a standard sample holder. Coherent scattering region for AuNPs was estimated using the Scherrer equation. The calculation was performed for the diffraction peak (111) of gold taking into account FWHM of the reference sample- $\mathrm{Si}$.

The UV-visible spectra of the solutions were recorded with SHIMADZU UV-1700 spectrophotometer.

The IR absorption spectra within the range 4,000$400 \mathrm{~cm}^{-1}$ were recorded with a Fourier transform spectrometer SCIMITAR FTS 2000 in a thin layer between $\mathrm{KBr}$ glass plates for the liquid reagent $\mathrm{C}_{16} \mathrm{H}_{34} \mathrm{O}_{2} \mathrm{PS}_{2} \mathrm{H}$ and in $\mathrm{KBr}$ tablets for the nanoparticle preparation.

Chemical CHN analysis of the preparations was made with the EURO EA 3000 instrument. Analysis for gold and sodium after the dissolution of the weighed portion of preparation in aqua regia, evaporation, and transfer into the solution of $2 \mathrm{M}$ $\mathrm{HCl}$ were carried out by means of atomic absorption in airacetylene flame using Hitachi Z-8000 instrument.

Thermogravimetric examination of the preparation was carried out using with thermobalance TG 2009 F1 Iris (NETZSCH) in a corundum crucible under the atmosphere of helium at the gas flow rate of $35 \mathrm{~mL} / \mathrm{min}$ and heating rate of $10^{\circ} \mathrm{C} / \mathrm{min}$.

\section{Results and discussion}

Isolation of nanoparticles by means of double sequential stabilization Destruction of micelles by chloroform without adding AOT causes rapid agglomeration of AuNPs even before DTPA is introduced. In the presence of chloroform, adsorption on particle surface is likely to be much weaker for nonionic TN-42 than for anionic surfactant AOT that provides intermediate stabilization of particles during micelle destruction and then is replaced by DTPA, which is a stronger protective reagent for chalcophilic gold (Fig. 1).

It was established by means of non-aqueous electrophoresis that, during the reduction of gold by hydrazine in TN42 micelles, the nanoparticles have a positive surface charge increasing linearly with an increase in the concentration of the reducing agent [37]. During the reduction of $\mathrm{Au}^{\mathrm{III}}$ and $\mathrm{Ag}^{\mathrm{I}}$ by hydrazine in AOT micelles, the charge of $\mathrm{Au}$ and Ag NPs is positive, too, and it increases with the dilution of AOT solution in decane by chloroform [14, 38]. On the basis of the results reported in the present work and those obtained previously, we can propose the following hypothetical mechanism of double sequential stabilization. Chloroform is a known reagent destroying the micelles of oxyethylated surfactants in alkanes even in insignificant concentrations; it is used for concentrating precious metals in the form of salt solutions [39] and NPs [40]. In the case of NPs, chloroform desorbs a part of the molecules of nonionic TN-42 from the surface of AuNPs, which causes a decrease in the osmic and steric components of disjoining pressure and causes subsequent coagulation and agglomeration of NPs [37]. The presence of AOT in chloroform
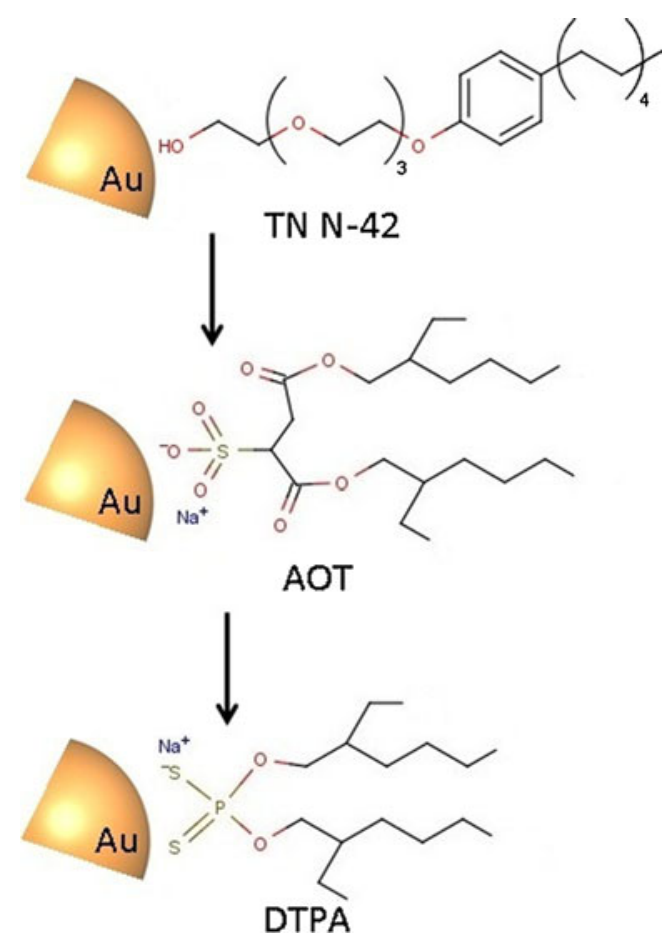

Fig. 1 Scheme of sequential stabilization of AuNPs with the help of TN-42, AOT, and DTPA 
causes more rapid diffusion of the surface-active anion to the positively charged nanoparticle and subsequent adsorption due to the electrostatic attraction. The protective surface layer of surfactant on a nanoparticle is partially recovered, and coagulation is suppressed. Diffusion of uncharged DTPA molecules is slower, and adsorption at the initial stage is due only to Van der Waals attraction. However, with time, DTPA molecules start to form strong, preferably donor-acceptor bonds with AuNPs due to sulfur atoms possessing high affinity to chalcophilic gold [33], and displace AOT from the surface layer. Thus, AOT provides intermediate stabilization of AuNPs. The surface DTPA layer in the organic environment containing chloroform protects nanoparticles only from agglomeration but does not protect them from coagulation, so as time goes by, large aggregates (floccules) of NPs undergo sedimentation and get isolated as the powder. The presence of chemisorbed surface layer of DTPA (with the hydrophobic layer of hydrocarbon groups turned outward) creates the possibility for gold nanoparticle to get peptized in nonpolar solvents. Note that our considerations have a hypothetical character; a more extensive investigation of the mechanism of double sequential stabilization is a part of our future work.

Properties of the preparation The AuNPs powder is hydrophobic and gets re-dispersed in weakly polar organic solvents, in particular in toluene, with the formation of blue colloidal solutions. The color and absorption spectrum of the solution exhibiting a broad band with the maximum at about $650 \mathrm{~nm}$ (Fig. 2) provide evidence of particle aggregation [41]. During re-dispersion through manual agitation, aggregates with a size up to $d_{\mathrm{ha}}=600 \pm 50 \mathrm{~nm}$ are detected by means of DLS in the colloidal solution of

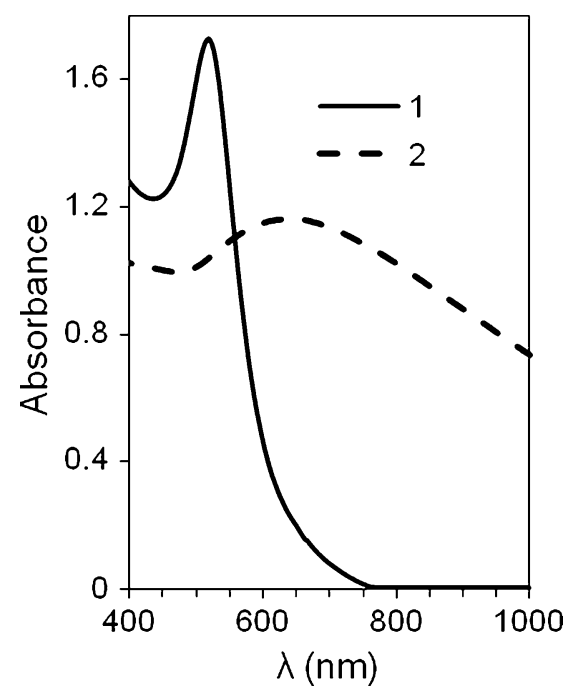

Fig. 2 UV-vis spectra of (1) AuNPs in micellar solution of TN-42 during synthesis and (2) AuNPs powder re-dispersed in toluene the preparation; under the ultrasonic treatment of the solution with moderate intensity the size decreases to $d_{\mathrm{ha}}=240 \pm$ $20 \mathrm{~nm}$. A similar trend is observed also by means of AFM. The images of the films (Fig. 3a, b) obtained as a result of the evaporation of toluene solution of the preparation on mica surface before ultrasonic treatment display the aggregates of ellipsoid shape; their major and minor axes are estimated as $d_{1}=225 \pm 15$ and $d_{2}=200 \pm 18 \mathrm{~nm}$, respectively, for the number of measurements $N=102$ (Fig. 3c, d). After ultrasonic treatment of the solution, the size of aggregates decreased to $40-50 \mathrm{~nm}$. Thus, aggregation of particles in the preparation does not lead to their agglomeration and merging.

The IR spectra of DTPA and the AuNPs preparation are presented in Fig. 4. The spectra contain the bands characteristic of dialkyldithiophosphoric acids [42-44]: the bands of asymmetric bending vibrations of $\mathrm{CH}_{3}$ and $\mathrm{CH}_{2}$ groups, $1,463 \mathrm{~cm}^{-1}$ AuNPs $\left(1,463 \mathrm{~cm}^{-1}\right.$ DTPA); symmetric vibrations of $\mathrm{CH}_{3}$ and $\mathrm{CH}_{2}$ groups, $1,381 \mathrm{~cm}^{-1}$ $\left(1,380 \mathrm{~cm}^{-1}\right)$; vibrations of the $(\mathrm{P})-\mathrm{O}-\mathrm{C}$ fragment, $1,018 \mathrm{~cm}^{-1}\left(1,019 \mathrm{~cm}^{-1}\right)$; and stretching vibrations of thiophosphoryl group $P=\mathrm{S}, 671 \mathrm{~cm}^{-1}\left(669 \mathrm{~cm}^{-1}\right)$. The difference is the presence of a broad band of stretching vibrations of $(\mathrm{P})-\mathrm{S}-\mathrm{H}$ bond in the region of 2,550 $2,650 \mathrm{~cm}^{-1}$ in the spectrum of DTPA, while this band does not appear in the spectrum of AuNPs. This means that the protective coating of AuNPs is composed of $\mathrm{C}_{16} \mathrm{H}_{34} \mathrm{O}_{2} \mathrm{PS}_{2}^{-}$anions adsorbed on the surface of particle nuclei, which explains the hydrophobic character of the formed nanoparticles.

The XRD data show that two crystal phases are present in the preparations: metal $\mathrm{Au}$ and $\mathrm{NaCl}$ (Fig. 5). The source of $\mathrm{Cl}^{-}$ions is the initial form $\mathrm{AuCl}_{4}^{-}$, while the source of $\mathrm{Na}^{+}$is AOT during the isolation of AuNPs. Judging from broadening of diffraction peaks, the gold phase is ultrafine. The coherent scattering region for AuNPs in the preparation obtained at $V_{\mathrm{s}} / V_{\mathrm{o}}=0.02$ was estimated to be at a level of 3-4 $\mathrm{nm}$.

For the preparation of AuNPs obtained at $V_{\mathrm{s}} / V_{\mathrm{o}}=0.02$, elemental analysis was carried out. The results are presented in Table 2. According to the gold content of the preparation $37 \%$, the yield of the product calculated for the metal is estimated on the basis of several experiments to be within the range $90-98 \%$. The presence of nitrogen in the preparation is explained by the use of hydrazine as the reducing agent in the synthesis of AuNPs. Because of a large excess of the reducing agent, it is assumed that the major form of nitrogen in the preparation is directly $\mathrm{N}_{2} \mathrm{H}_{4}$.

The TGA data are in satisfactory agreement with the elemental analysis. Three steps of thermolysis of AuNPs are observed during heating the sample of the preparation in helium atmosphere (Fig. 6a). The first step relates to the temperature range of $90-210^{\circ} \mathrm{C}$, and the weight loss of 

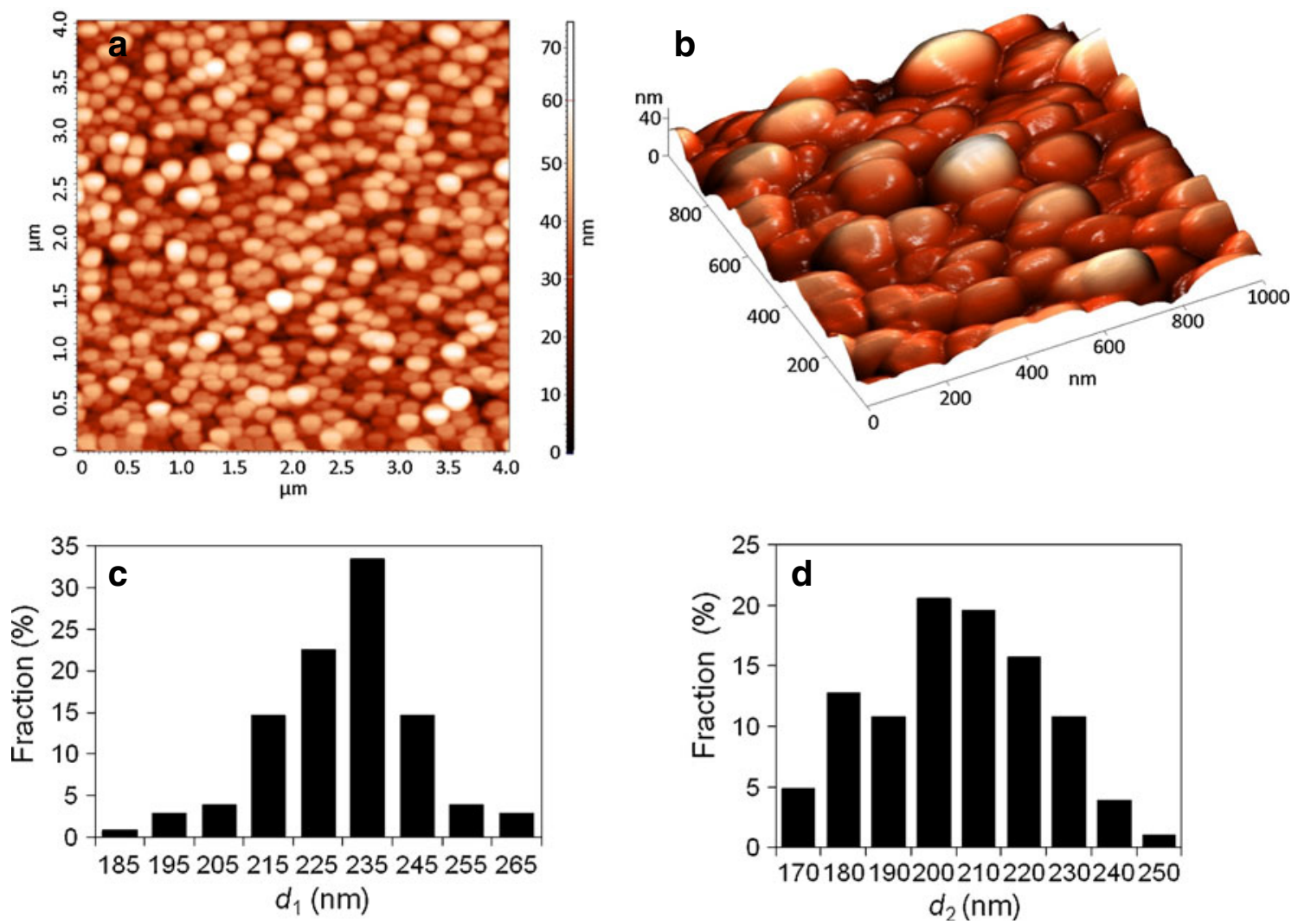

Fig. 3 a $2 \mathrm{D}$ and b $3 \mathrm{D}$ AFM images of ellipsoid aggregates of AuNPs obtained at $V_{\mathrm{s}} / V_{\mathrm{o}}=0.02$, and the size distribution for their $\mathbf{c}$ major and d minor axes

$2.1 \%$ is observed, which corresponds to the detachment of hydrazine. Its calculated content is equal to $1.9 \%$ (Table 2 ). At the second stage $\left(210-430^{\circ} \mathrm{C}\right)$ and the third one $(430$ $735^{\circ} \mathrm{C}$ ), the weight losses are $3.1 \%$ and $7.1 \%$, respectively. The total weight loss at the second and the third stages $(10.2 \%)$ can be related to the detachment of the protective reagent; its mass fraction in the preparation is estimated to be $10.6 \%$ as suggested by the data of elemental analysis. Therefore, the whole DTPA of the AuNPs sample is completely desorbed at $210-735^{\circ} \mathrm{C}$. According to XRD

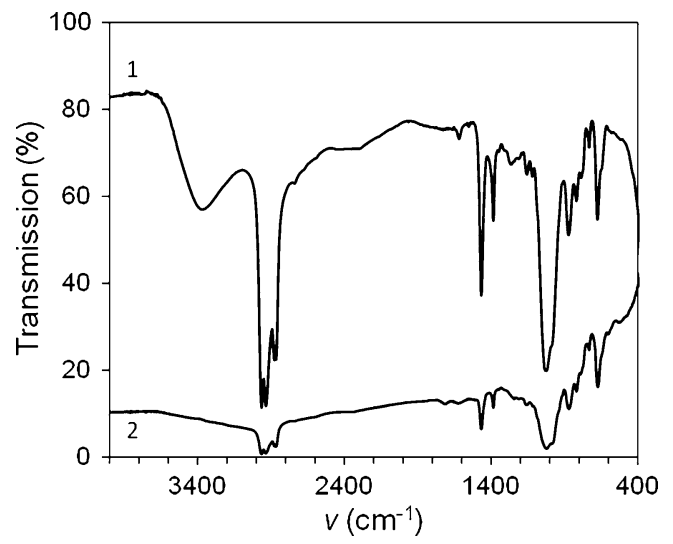

Fig. 4 IR spectra of (1) DTPA and (2) AuNPs powder data, the product of thermal decomposition at $735^{\circ} \mathrm{C}$ is a mixture of the phases of metal $\mathrm{Au}$ and $\mathrm{NaCl}$ (Fig. 6b). When heated above $735^{\circ} \mathrm{C}$ weight loss is observed due to sublimation of $\mathrm{NaCl}$. The residual mass is $35.1 \%$, which roughly corresponds to the $\mathrm{Au}$ content in the product $(37 \%)$.

Characterization of AuNPs One can clearly see the chain structure of the aggregates in the TEM micrograph (Fig. 7a, b), which is a characteristic of the ensembles of nano-

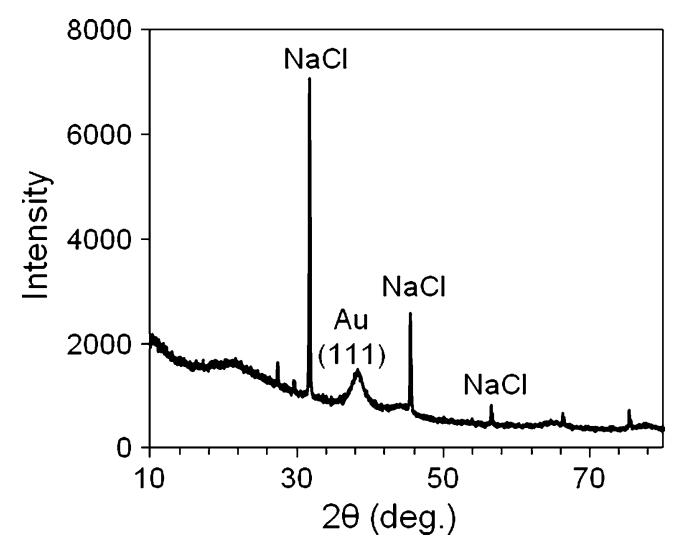

Fig. 5 Diffraction patterns of AuNPs powder prepared at $V_{\mathrm{s}} / V_{\mathrm{o}}=0.02$ 
Table 2 Results of the analysis of AuNPs powder $\left(d_{\mathrm{Au}}=8.8 \pm 1.5 \mathrm{~nm}\right)$ and calculated element content for $\left\{\mathrm{Au}\left(\mathrm{C}_{16} \mathrm{H}_{34} \mathrm{O}_{2} \mathrm{PS}_{2} \mathrm{Na} 2 \mathrm{~N}_{2} \mathrm{H}_{4}\right)_{0.16}+\right.$ $4.54 \mathrm{NaCl}\}(\mathrm{FW}=532)$

\begin{tabular}{lcc}
\hline Element & Found (wt.\%) & Calculated (wt.\%) \\
\hline $\mathrm{Au}$ & $37 \pm 1$ & 37.02 \\
$\mathrm{C}$ & $6.1 \pm 0.2$ & 5.78 \\
$\mathrm{H}$ & $1.0 \pm 0.2$ & 1.27 \\
$\mathrm{~N}$ & $1.7 \pm 0.2$ & 1.68 \\
$\mathrm{Na}$ & $23.2 \pm 0.7$ & 20.31 \\
\hline
\end{tabular}

${ }^{\text {a }}$ Variation range is used as the error value

particles and conforms with the UV-vis spectra of colloidal solutions of AuNPs powder re-dispersed in toluene. The gold nuclei of the particles have spherical shape and a narrow size distribution (Table 1). The EDX spectrum of individual AuNPs (Fig. 7c), in addition to the signals from $\mathrm{C}$ and $\mathrm{Cu}$, which are due to the substrate, exhibits intense signals of $\mathrm{Au}$ (lines $\mathrm{Au} M_{\alpha}$ and $\mathrm{Au} L_{\alpha}$ ), as well as the elements present in the protective reagent $\mathrm{C}_{16} \mathrm{H}_{34} \mathrm{O}_{2} \mathrm{PS}_{2} \mathrm{H}$ : $\mathrm{O}\left(\mathrm{O} K_{\alpha}\right.$ line $), \mathrm{P}\left(\mathrm{P} K_{\alpha}\right.$ line $)$, and $\mathrm{S}$ ( $\mathrm{S} K_{\alpha}$ line $)$. In addition to AuNPs, the TEM micrograph contains separate cubic microcrystals of the salt, with the edges 80-150 nm long (Fig. 7g) Their EDX spectrum (Fig. 7h) contains the signals of $\mathrm{Na}\left(\mathrm{Na} K_{\alpha}\right.$ line $)$ and $\mathrm{Cl}\left(\mathrm{Cl} K_{\alpha}\right.$ line $)$. The salt crystals create a strong background, so the signals of $\mathrm{Na}$ and $\mathrm{Cl}$ manifest themselves in the EDX spectrum of gold particles (Fig. 7c). Thus, the results of TEM and EDX analysis confirm the XRD data concerning the presence of the dispersed $\mathrm{NaCl}$ phase in the preparations of AuNPs.

One can see in the high-resolution TEM (HRTEM) micrograph that the nuclei of nanoparticles are single crystals (Fig. 7d). Interplanar spacings are equal to $2.35 \AA$ and relate to the distance $d_{111}$ of metal gold (Fig. 7e, f). The absence of twinning structures in AuNPs, as well as the narrow size distribution of the particles (17-18\%), confirms our idea of the kinetic mechanism according to which the growth of AuNPs occurs in separate micelles independently and synchronously as a result of the addition of new gold atoms to the particles but not due to the addition of particles from neighboring micelles [45].

The average values of AuNPs nucleus diameter, determined by means of DLS in the micellar solution of TN-42 during synthesis, are in good agreement with TEM data for individual particles in the preparations (Table 1). So, the change of the protective reagent for the particles from TN42 sequentially for AOT and then for DTPA during the isolation of the powder allows one to conserve the size of AuNPs nucleus, obtained during the micellar synthesis. At the same time, under the chosen synthesis conditions, the size of AuNPs is almost two times as large as the size of the water nuclei of initial micelles. A similar phenomenon was observed previously by other researchers [46]. Therefore, the micelles of oxyethylated surfactants like TN-42 are not rigid templates but undergo structural rearrangements while the particles get formed.

On the basis of the results of XRD, IR, ED and elemental analysis, stoichiometry of the molecules of protective reagent, and the principle of electric neutrality, it may be concluded that the preparation is a mixture of AuNPs and the salt with the molar ratio $\mathrm{Au} / \mathrm{NaCl} \approx 1: 4.54$, and the gross composition of AuNPs per one gold atom is estimated as $\mathrm{Au}\left(\mathrm{C}_{16} \mathrm{H}_{34} \mathrm{O}_{2} \mathrm{PS}_{2} \mathrm{Na} 2 \mathrm{~N}_{2} \mathrm{H}_{4}\right)_{0.16}$; the number of gold atoms in one particle is $\sim 21,000$ in the case when the metal nucleus has a diameter $d_{\mathrm{Au}}=8.8 \mathrm{~nm}$. The total number of gold atoms in a particle was determined as $N_{\mathrm{t}}=$ $V_{\mathrm{Au}} / V_{\mathrm{a}}$, where $V_{\mathrm{Au}}=(1 / 6) \cdot \pi \cdot d_{\mathrm{Au}}{ }^{3}=357 \mathrm{~nm}^{3}$ is the volume of gold nanoparticle and $V_{\mathrm{a}}=0.016962 \mathrm{~nm}^{3}$ is the atomic volume of gold. The resulting value $N_{\mathrm{t}}=21,036$ agrees with the calculated value of $N_{\mathrm{t}}^{\text {calc }}$ for the "magic" particle with completely filled 18 atomic layers having the fcc structure.
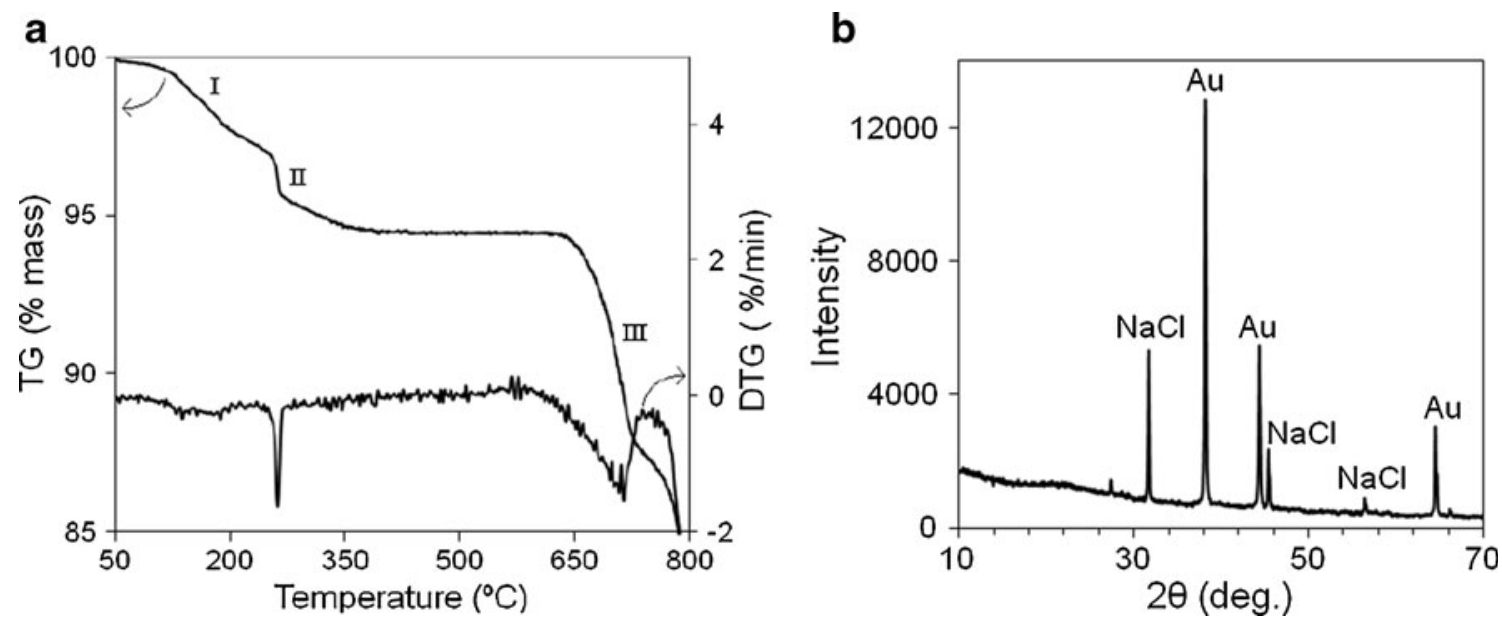

Fig. 6 a Thermogravimetric data for AuNPs powder prepared at $V_{\mathrm{s}} / V_{\mathrm{o}}=0.02$, and $\mathbf{b}$ diffraction patterns of thermolysis product at $735^{\circ} \mathrm{C}$ 

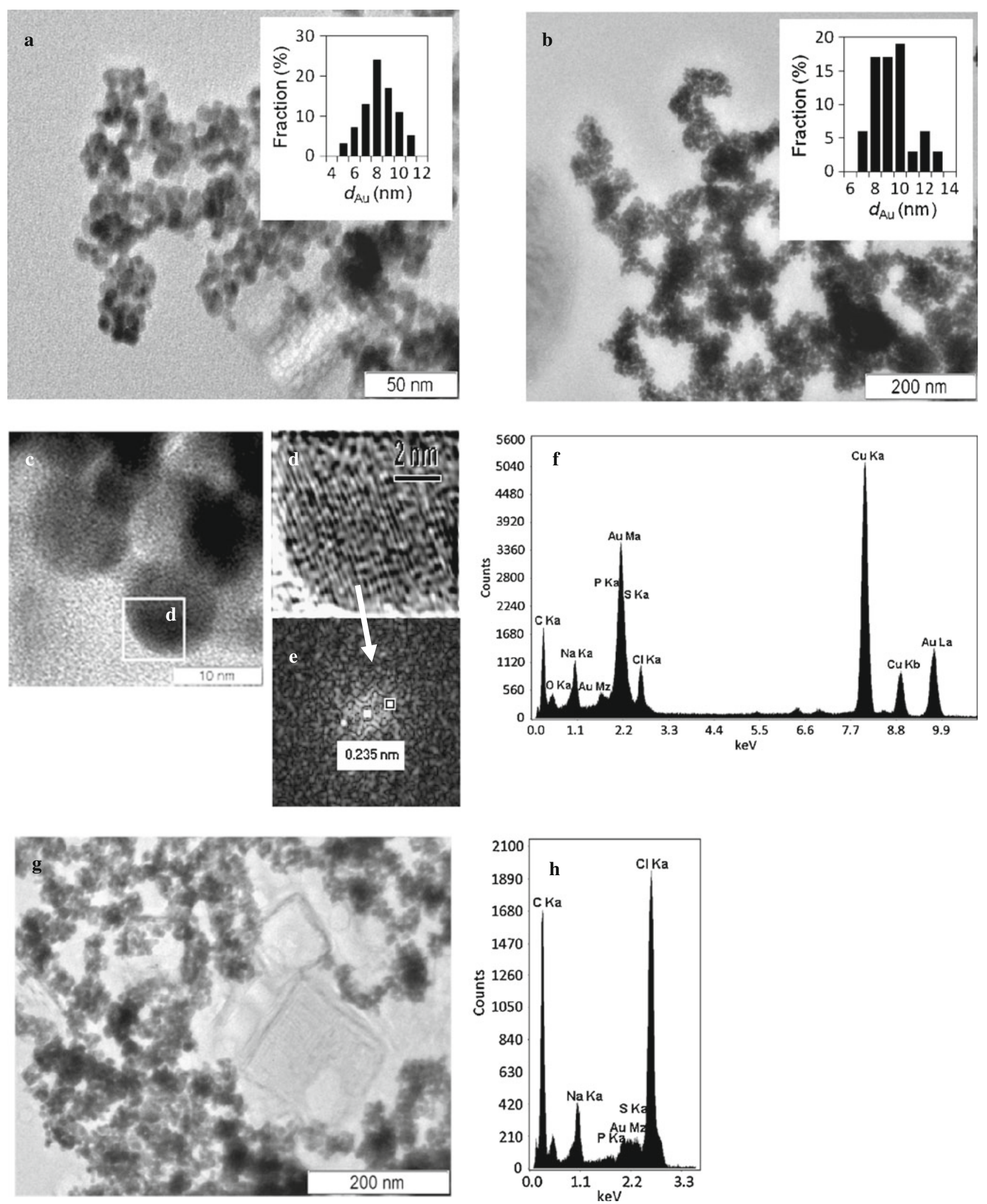

Fig. 7 TEM images and the size distribution for AuNPs prepared at a $V_{\mathrm{s}} / V_{\mathrm{o}}=0.005$ and $\mathbf{b} 0.02$; $\mathbf{c}$, d HRTEM, e FFT, and $\mathbf{f}$ EDX for AuNPs prepared at $V_{\mathrm{s}} / V_{\mathrm{o}}=0.02 ; \mathbf{g}$ TEM and $\mathbf{h} \mathrm{EDX}$ of $\mathrm{NaCl}$ microcrystals 
For such a particle, the number of surface atoms and the total number of gold atoms are $N_{\mathrm{s}}^{\mathrm{calc}}=10 \cdot n^{2}+2=3,242$ and $N_{\mathrm{t}}^{\text {calc }}=1+\sum\left(10 \cdot n^{2}+2\right)=21,127$, where $n=18$ is the number of a layer [47]. The ratio $N_{\mathrm{s}}^{\text {calc }} / N_{\mathrm{t}}^{\text {calc }}=0.15$ is close to the stoichiometric value $\mathrm{C}_{16} \mathrm{H}_{34} \mathrm{O}_{2} \mathrm{PS}_{2}{ }^{-} / \mathrm{Au}=0.16$ in the preparation. Assuming the monolayer adsorption of the protective reagent, this means that there is approximately one $\mathrm{C}_{16} \mathrm{H}_{34} \mathrm{O}_{2} \mathrm{PS}_{2}{ }^{-}$anion per one surface gold atom; the negative charge of the anion is compensated by $\mathrm{Na}^{+}$cation. In addition, we assume that two $\mathrm{N}_{2} \mathrm{H}_{4}$ molecules form hydrogen bonds with two oxygen atoms in $\mathrm{C}_{16} \mathrm{H}_{34} \mathrm{O}_{2} \mathrm{PS}_{2}{ }^{-}$.

\section{Conclusions}

We present the synthesis method for AuNPs in reverse micelles of nonionic oxyethylated surfactant TN-42 with the subsequent isolation of nanoparticles as powder. To isolate nanoparticles from the micellar solution, the micelles were destroyed with a polar solvent, chloroform, in the presence of a surfactant, AOT (intermediate stabilizing agent, and a protective reagent, DTPA (the final surface stabilizing agent), which possesses high affinity to gold due to S-containing functional groups. The developed method of double sequential stabilization allows one to isolate AuNPs from micelles without changing the size of particle nuclei. The yield of the product with respect to gold is $90-98 \%$.

The resulting preparations contain AuNPs and $\mathrm{NaCl}$ microcrystals. The NPs consist of the metal nucleus and the protective shell. The nuclei are gold single crystals having the spherical shape and a narrow size distribution with the average diameters $7.7 \pm 1.4$ and $8.8 \pm 1.4 \mathrm{~nm}$, which are two times as large as the diameters of aqueous nuclei of initial TN-42 micelles 3.6 and $4.6 \mathrm{~nm}$. The shell is composed of chemisorbed $\mathrm{C}_{16} \mathrm{H}_{34} \mathrm{O}_{2} \mathrm{PS}_{2}{ }^{-}$anions that have $\mathrm{Na}^{+}$cations as the counter-ions; in addition, due to their oxygen atoms, they participate in hydrogen bonding with two $\mathrm{N}_{2} \mathrm{H}_{4}$ molecules. Assuming monolayer adsorption, there is approximately one $\mathrm{C}_{16} \mathrm{H}_{34} \mathrm{O}_{2} \mathrm{PS}_{2}{ }^{-}$anion per one surface gold atom.

The preparation is a hydrophobic powder of aggregated but not agglomerated AuNPs peptizing in weakly polar organic solvents with the formation of colloid solutions. These solutions can be used to deposit the layers of AuNPs on various substrates and to impregnate porous matrices.

Acknowledgments This work was supported by the Russian Foundation for Basic Research (projects nos. 05-03-32308, 09-0300511).

Open Access This article is distributed under the terms of the Creative Commons Attribution License which permits any use, distribution and reproduction in any medium, provided the original author(s) and source are credited.

\section{References}

1. Schmid G (2004) Nanoparticles: from theory to application. Wiley-VCH, Weinheim

2. Grisel R, Weststrate K-J, Gluhoi A, Nieuwenhuys BE (2002) Catalysis by gold nanoparticles. Gold Bulletin 35(2):39-45

3. Bretschneider JC, Reismann M, Plessen GV, Simon U (2009) Photothermal control of the activity of HRP-functionalized gold nanoparticles. Small 22:2549-2553. doi:10.1002/smll.200900544

4. Ofir Y, Samanta B, Rotello VM (2008) Polymer and biopolymer mediated self-assembly of gold nanoparticles. Chem Soc Rev 37:1814-1825. doi:10.1039/B712689C

5. Boisselier E, Astruc D (2009) Gold nanoparticles in nanomedicine: preparations, imaging, diagnostics, therapies and toxicity. Chem Soc Rev 38(6):1759-1782. doi:10.1039/b806051g

6. Ji X, Song X, Li J, Bai Y, Yang W, Peng X (2007) Size control of gold nanocrystals in citrate reduction:the third role of citrate. $\mathrm{J}$ Am Chem Soc 129(45):13939-13948. doi:10.1021/ja074447k

7. Ojea-Jiménez I, Romero FM, Bastu's NG, Puntes V (2010) Small gold nanoparticles synthesized with sodium citrate and heavy water: insights into the reaction mechanism. J Phys Chem C 114:1800-1804. doi:10.1021/jp9091305

8. Rao CNR, Kulkarni GU, Thomas PJ, Agrawal VV, Saravanan P (2003) Films of metal nanocrystals formed at aqueous-organic interfaces. J Phys Chem B 107:7391-7395. doi:10.1021/ jp0340111

9. Vitale F, Fratoddi I, Battocchio C, Piscopiello E, Tapfer L, Russo MV, Polzonetti G, Giannini C (2011) Mono- and bi-functional arenethiols as surfactants for gold nanoparticles: synthesis and characterization. Nanoscale Res Lett 6:103-111. doi:10.1186/ 1556-276X-6-103

10. Li Y, Zaluzhna O, Xu B, Gao Y, Modest JM, Tong YJ (2011) Mechanistic insights into the Brust-Schiffrin two-phase synthesis of organo-chalcogenate-protected metal nanoparticles. J Am Chem Soc 133:2092-2095. doi:10.1021/ja1105078

11. Abecassis B, Testard F, Zemb T (2009) Gold nanoparticle synthesis in worm-like catanionic micelles: microstructure conservation and temperature induced recovery. Soft Matter 5:974978. doi:10.1039/B816427D

12. Smetana AB, Wang JS, Boeckl J, Brown GJ, Wai CM (2007) Fine-tuning size of gold nanoparticles by cooling during reverse micelle synthesis. Langmuir 23(21):10429-10432. doi:10.1021/ la701229q

13. Herrera AP, Resto O, Briano JG, Rinaldi C (2005) Synthesis and agglomeration of gold nanoparticles in reverse micelles. Nanotechnology 6:S618-S625. doi:10.1088/0957-4484/16/7/04

14. Bulavchenko AI, Pletnev DN (2008) Electrophoretic concentration of nanoparticles of gold in reversed micellar solutions of AOT. J Phys Chem C 112:16365-16369. doi:10.1021/jp805268w

15. Chiang C-L, Hsu M-B, Lai L-B (2004) Control of nucleation and growth of gold nanoparticles in AOT/Span80/isooctane mixed reverse micelles. J Solid State Chem 177(11):3891-3895. doi:10.1016/j.jssc.2004.07.003

16. Tatarchuk VV, Bulavchenko AI (2004) Formation and coagulation kinetics of gold nanoparticles in AOT reverse micelles. Russ $\mathrm{J}$ Inorg Chem 49(8):1225-1337

17. Tatarchuk VV, Bulavchenko AI, Druzhinina IA (2006) Formal kinetics of growth of nanosized silver particles upon silver nitrate reduction with sodium citrate in a reverse micellar solution of AOT. Russ J Inorg Chem 51(11):1836-1839. doi:10.1134/ S0036023606110222

18. Tatarchuk VV, Bulavchenko AI, Druzhinina IA (2007) Dissolution kinetics of silver metal nanoparticles in their reaction with nitric acid in a reverse micelle solution of AOT. Russ J Inorg Chem 52(8):1284-1288. doi:10.1134/S0036023607080207 
19. Tatarchuk VV, Bulavchenko AI, Druzhinina IA (2008) Kinetics of oxidative dissolution of gold nanoparticles in Triton N-42 reversed micelles. Russ J Inorg Chem 53(6):974-979. doi:10.1134/S0036023608060284

20. Tatarchuk VV, Bulavchenko AI, Druzhinina IA (2009) Kinetics of dissolution of silver nanoparticles inside Triton N-42 reversed micelles. Russ J Inorg Chem 54(10):1678-1683. doi:10.1134/ S0036023609100295

21. Tatarchuk VV, Bulavchenko AI, Druzhinina IA, Sergievskaya AP (2011) Effect of dioctyl sulfide on the kinetics of oxidative dissolution of gold nanoparticles in Triton N-42 reverse micelles. Russ J Inorg Chem 56(5):808-815. doi:10.1134/ S0036023611050251

22. Martin MN, Basham JI, Chando P, Eah S-K (2010) Charged gold nanoparticles in non-polar solvents: 10-min synthesis and 2D selfassembly. Langmuir 26(10):7410-7417. doi:10.1021/la100591h

23. Garg N, Mohanty A, Lazarus N, Schultz L, Rozzi TR, Santhanam S, Weiss L, Snyder JL, Fedder GK, Jin R (2010) Robust gold nanoparticles stabilized by trithiol for application in chemiresistive sensors. Nanotechnology 21:405501-405506. doi:10.1088/ 0957-4484/21/40/405501

24. Manea F, Bindoli C, Polizzi S, Lay L, Scrimin P (2008) Expeditious synthesis of water-soluble, monolayer-protected gold nanoparticles of controlled size and monolayer composition. Langmuir 24:4120-4124. doi:10.1021/la703558y

25. Zhang S, Leem G, Lee TR (2009) Monolayer-protected gold nanoparticles prepared using long-chain alkanethioacetates. Langmuir 25(24):13855-13860. doi:10.1021/la901847s

26. Subramaniam C, Tom RT, Pradeep T (2005) On the formation of protected gold nanoparticles from $\mathrm{AuCl}_{4}^{-}$by the reduction using aromatic amines. J Nanopart Res 7:209-217. doi:10.1007/s11051005-0315-0

27. Sardar R, Bjorge NS, Shumaker-Parry JS (2008) pH-Controlled assemblies of polymeric amine-stabilized gold nanoparticles. Macromolecules 41:4347-4352. doi:10.1021/ma800407s

28. Shem PM, Sardar R, Shumaker-Parry JS (2009) One-step synthesis of phosphine-stabilized gold nanoparticles using the mild reducing agent 9-BBN. Langmuir 25(23):13279-13283. doi:10.1021/la903003n

29. Alimarin IP, Rodionova TV, Ivanov VM (1989) Extraction with thio and dithio phosphorus acids. Russ Chem Rev 58:863. doi:10.1070/RC1989v058n09ABEH003483

30. Balakireva NA, Novosel'tseva LA, Levin IS (1975) Extraction of gold by di(2-ethylhexyl)dithiophosphorous acid. Zh Anal Khim 30:684, in Russian

31. Tsimbalist VG, Anoshin GN, Mitkin VN, Razvorotneva LI, Golovanova NP (2000) Observations on new approaches for the determination of platinum-group elements, gold and silver in different geochemical samples from Siberia and the Far East. J Geostand Geoanalysis 24(2):171-182. doi:10.1111/j.1751908X.2000.tb00769.X

32. Yukhin YM, Udalova TA, Tsimbalist VG (1985) Nonflame AAS determination of the noble metals with an extraction pre- concentration by mixture of di-2-ethylhexyldithiophosphorous acid and n-oktylanyline. Zh Anal Khim 40:850-854 (in Russian)

33. Puddephatt RJ (1978) The chemistry of gold. Elsevier, Amsterdam

34. Zulauf M, Eicke HF (1979) Inverted micelles and microemulsions in the ternary system water/aerosol-OT/isooctane as studied by photon correlation spectroscopy. J Phys Chem 83(4):480-486. doi: $10.1021 / \mathrm{j} 100467 \mathrm{a} 011$

35. Bulavchenko AI, Batishcheva EK, Podlipskaya TY, Torgov VG (1998) Colloid-chemical interactions during the process of metal concentration by reverse micelles of ethoxylated surfactants: a geometrical approach. Colloid J Russian Acad Sci 60(2):152-160

36. Schönfeld N (1967) Surface active ethylene oxide adducts. Pergamon Press, Oxford

37. Bulavchenko AI, Arymbaeva AT, Tatarchuk VV (2008) The kinetics of synthesis and mechanism of coagulation of gold nanoparticles in Triton N-42 reverse micelles. Russ J Phys Chem A 82(5):801-806. doi:10.1134/S003602440805018X

38. Bulavchenko AI, Popovetsky PS (2010) The electrokinetic potential of nanoparticles in reverse AOT micelles: photometric determination and role in the processes of heterocoagulation, separation, and concentration. Langmuir 26(2):736-742. doi:10.1021/la903583r

39. Bulavchenko AI, Batishcheva EK, Torgov VG (1995) Metal concentration by reversed micelles. Sep Sci Technol 30(2):239 246

40. Bulavchenko AI, Tatarchuk VV, Bulavchenko OA, Arymbaeva AT (2005) Gold concentration by Triton N-42 reversed micelles. Russ J Inorg Chem 50(2):786-790

41. Lazarides AA, Schatz GC (2000) DNA-linked metal nanosphere materials: structural basis for the optical properties. J Phys Chem B 104(3):460-467. doi:10.1021/jp992179+

42. Vorsina IA, Kolyshev AN, Eremeeva TP (1976) Vibrational spectra of di-2-ethilhehylditiophosphoric acid and spectral characteristics of the $P=\mathrm{S}$ bond. J Applied spectroscopy 21(1):926930. doi:10.1007/BF00606491

43. Eremeeva TP, Vorsina IA (1976) Raman spectra of bis(2-ethylhexyl) hydrogen phosphorodithioate. Bull Acad Sci USSR Div Chem Sci 25(6):1224-1228. doi:10.1007/BF00928056

44. Cote G, Bauer D (1984) Hydrolysis of the O, O-dialkyl phosphorodithioic acids used as extractants in liquid-liquid systems. Anal Chem 56(12):2153-2157. doi:10.1021ac00276a040

45. Tatarchuk VV, Sergievskaya AP, Druzhinina IA, Zaikovsky VI (2011) Kinetics and mechanism of the growth of gold nanoparticles by reduction of tetrachloroauric acid by hydrazine in Triton N-42 reverse micelles. J Nanopart Res. doi:10.1007/ s11051-011-0481-1

46. Arcoleo V, Turco Liveri V (1996) AFM investigation of gold nanoparticles synthesized in water/AOT/n-heptane microemulsions. Chem Phys Lett 258:223-227. doi:10.1016/0009-2614(96) 00669-0

47. Teo BK, Sloane NJA (1985) Magic numbers in polygonal and polyhedral clusters. Inorg Chem 24(26):4545-4558. doi:10.1021/ ic00220a025 